\title{
A LONG-TERM REVIEW OF CHILDREN WITH CONGENITAL AND ACQUIRED UPPER LIMB DEFICIENCY
}

\author{
T. R. SCOTLAND, H. R. GALWAY
}

\author{
From the Ontario Crippled Children's Centre
}

\begin{abstract}
A long-term review of 131 children fitted with upper limb prostheses at the Ontario Crippled Children's Centre between 1965 and 1975 is reported. There were 116 children with congenital deficiencies and 15 who had had amputations. Follow-up ranged from 7 to 17 years. A total of 42 children had abandoned their prostheses, 37 of whom had congenital deformities and five were amputees. The level of deficiency was of fundamental importance in determining whether the prosthesis would be accepted; in the forearm, the longer the stump, the more likely it was that the child would discard the prosthesis. Overall, 50 per cent of children fitted over the age of two years abandoned their prostheses compared with only 22 per cent of patients who had been fitted before the age of two years. The highest drop-out rate was at the age of 13 years when the children became more conscious of their cosmetic appearance. Suggestions for reducing the high drop-out rate in the early teens are put forward.
\end{abstract}

The Ontario Crippled Children's Centre is a provincial rehabilitation centre for patients up to the age of 19 years. At this centre the management of handicapped children is undertaken and guided by teams of specialists at regular clinics. One such clinic, the Prosthetic Clinic, cares for the child amputee.

The purpose of this paper is to review the long-term results of children with upper limb deficiencies, whether congenital or the result of trauma, who had been fitted with a prosthesis between 1965 and 1975.

In 1953, Aitken and Frantz reported that only one out of 20 patients with congenital upper limb deficiencies had been fitted with a prosthesis before being seen at their clinic, despite the fact that the average age at their first attendance was 13 years. However, over the past few years, much interest has been shown in the early fitting of prostheses (Brooks and Shaperman 1965; Fisher 1976; Sörbye 1980). Early prosthetic fitting is reported to improve the prosthetic tolerance and the functional abilities of the child (Lund 1958).

In the study by Brooks and Shaperman (1965), it was concluded that the chances of a prosthesis being accepted are greater if the child is fitted before the age of two years. However, at review, the oldest patient in their series was aged 11 years, leaving the question of prosthetic acceptance in adolescence and early adult life unanswered.

T. R. Scotland, BSc, MB ChB, FRCS Ed, Senior Orthopaedic Registrar, Grampian Health Board

9 Woodend Drive, Aberdeen AB2 6Y5, Scotland.

H. R. Galway, BA, MD, FRCS (C), Chief

Division of Orthopaedics, St Joseph's Health Centre, 30 The Queensway, Toronto, Ontario, Canada M6R 1B5.

Requests for reprints should be sent to Dr H. R. Galway.

(C) 1983 British Editorial Society of Bone and Joint Surgery 0301-620X/83/3049-0346\$2.00
Accordingly, we feel there is a strong need for providing a long-term study of prosthetic wear through childhood and adolescence into adult life.

\section{CLINICAL MATERIAL}

One hundred and thirty-one children with upper limb deficiencies were studied; there were 74 boys and 57 girls. All had been fitted with a prosthesis at the Ontario Crippled Children's Centre between 1965 and 1975. The range of follow-up was from 7 to 17 years. The age of the patients at the final review ranged from 8 to 25 years.

Table I. Level of congenital upper limb deficiency in 116 patients

\begin{tabular}{|lccl|}
\hline Level of deficiency & Left & Right & Bilateral \\
\hline Shoulder disarticulation & 4 & 2 & 3 \\
Above elbow & 3 & 1 & 1 \\
Below elbow & 40 & 24 & - \\
Above wrist & 6 & 5 & - \\
Below wrist & 16 & 11 & - \\
\hline
\end{tabular}

Table II. Level of amputation in 15 patients

\begin{tabular}{|llll|}
\hline Level of amputation & Left & Right & Bilateral \\
\hline Shoulder disarticulation & 2 & 0 & - \\
Above elbow & 2 & 3 & 2 \\
Below elbow & 2 & 3 & - \\
Above wrist & 0 & 1 & - \\
\hline
\end{tabular}

One hundred and sixteen children had congenital limb deficiencies, of whom 85 had been fitted with a prosthesis before the age of two years. Fifteen children had sustained amputations as a result of trauma. Five had had an amputation after having a farming accident, three after complications of infection, two after high-tension electrical burns, 
two after train accidents, one after a boating accident, one after an accident with a lawnmower and one after an accident with a wringer. All the children who had had an amputation had been over the age of two years when fitted with a prosthesis; the average age was eight years, range 3 to 15 years. I and II

The levels of limb deficiency in 131 patients are shown in Tables

\section{METHOD}

Case records of the patients were reviewed. In addition, all patients were requested to complete a questionnaire about the use of their prosthesis. Every opportunity was taken to question patients at outpatient clinics, but this was not always possible as it was not thought to be appropriate to bring children in from remote locations for a special attendance at the centre.

Questions were asked relating to prosthetic wear at work, at home, and for social occasions. The number of hours the prosthesis was worn per day was recorded and particular attention paid to its functional use. Where a patient had stopped wearing his or her prosthesis, the reasons for discontinuing were noted and the age at which the child had stopped recorded. Because of the interest in efficacy of early fitting of prostheses, the age of the child when first fitted was related to the subsequent use or disuse of the prosthesis.

A functional classification of limb deficiency was employed and descriptive classifications avoided. Thus, patients with phocomelia, with one or two digits projecting from their trunks, were classified functionally as having a disarticulation at the shoulder. Patients with below-elbow deficiencies, whether congenital or acquired, were subdivided into two groups, those with a short stump, and those with a long stump (effectively an above-wrist amputation or deficiency), as deficiencies at these two levels resulted in very different functional abilities.

\section{RESULTS}

At the time of completion of this review in June, 1982, 103 patients were still at school or attending a college of further education. Twenty-eight had left school, of whom seven had failed to find employment. Only nine of the 21 patients who were employed found their prostheses of functional use at work.

Forty-two patients had stopped wearing their prosthesis: 37 in the congenital group (32 per cent), and five in the amputated group ( 33 per cent). The overall dropout rate was 32 per cent. The level of amputation was of fundamental importance in determining whether the prosthesis would be abandoned (Tables III and IV). In the congenital group it was noteworthy that by far the most successful group to fit were the children with a short below-elbow stump, with a drop-out rate of only 13 per cent. Patients with a long below-elbow stump, effectively an above-wrist deficiency, had a higher drop-out rate of 45 per cent while those with a below-wrist deficiency, with a mobile carpal remnant, had an even higher dropout rate of 59 per cent. In both the congenital and the amputated groups, shoulder disarticulations had a poor prognosis with respect to prosthetic use.

In the congenital group, 19 of the 85 patients fitted before the age of two years and 18 of the 31 patients fitted after the age of two stopped using their prostheses, a drop-out rate of 22 per cent and 58 per cent respectively.

Five of the 15 amputees, who had all been fitted
Table III. Number of patients that stopped using their prostheses in the group with congenital upper limb deficiency

\begin{tabular}{|c|c|c|c|}
\hline \multirow[b]{2}{*}{ Level of deficiency } & \multicolumn{2}{|c|}{ Number of patients } & \multirow{2}{*}{$\begin{array}{l}\text { Rate of } \\
\text { drop-out } \\
\text { (per cent) }\end{array}$} \\
\hline & Total fitted & Drop-outs & \\
\hline \multicolumn{4}{|l|}{ Unilateral } \\
\hline Shoulder disarticulation & 6 & 4 & 67 \\
\hline Above elbow & 4 & 3 & 75 \\
\hline Below elbow & 64 & 8 & 13 \\
\hline Above wrist & 11 & 5 & 45 \\
\hline Below wrist & 27 & 16 & 59 \\
\hline \multicolumn{4}{|l|}{ Bilateral } \\
\hline Shoulder disarticulation & 3 & 1 & 33 \\
\hline Above elbow & 1 & 0 & 0 \\
\hline
\end{tabular}

Table IV. Number of patients that stopped using their prostheses in the group with upper limb amputations

\begin{tabular}{|lll|}
\hline & \multicolumn{2}{l|}{ Number of patients } \\
\cline { 2 - 3 } Level of amputation & Total fitted & Drop-outs \\
\hline Unilateral & 2 & 2 \\
Shoulder disarticulation & 2 & 1 \\
Above elbow & 5 & 1 \\
Below elbow & 5 & 0 \\
Above wrist & 1 & 1 \\
Bilateral & & \\
Above elbow & 2 & \\
\hline
\end{tabular}

after the age of two years, had stopped wearing their prosthesis, a drop-out rate of 33 per cent. Overall, 23 of the 46 patients fitted after two years of age had discontinued wearing a prosthesis.

The age at which patients stopped wearing a prosthesis is shown in Figure 1. It can be seen that there was a steady drop-out from the ages of 6 to 11 years,

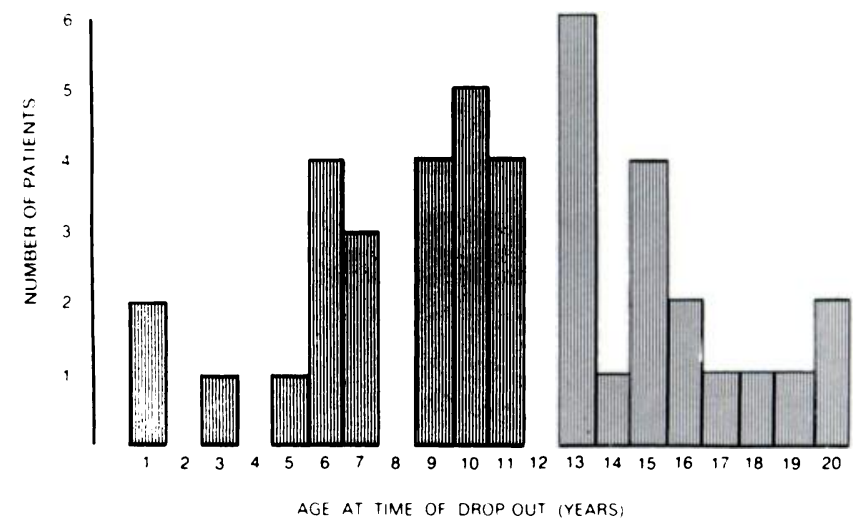

Fig. 1

Graph showing the age that the 42 patients stopped using their prostheses. 


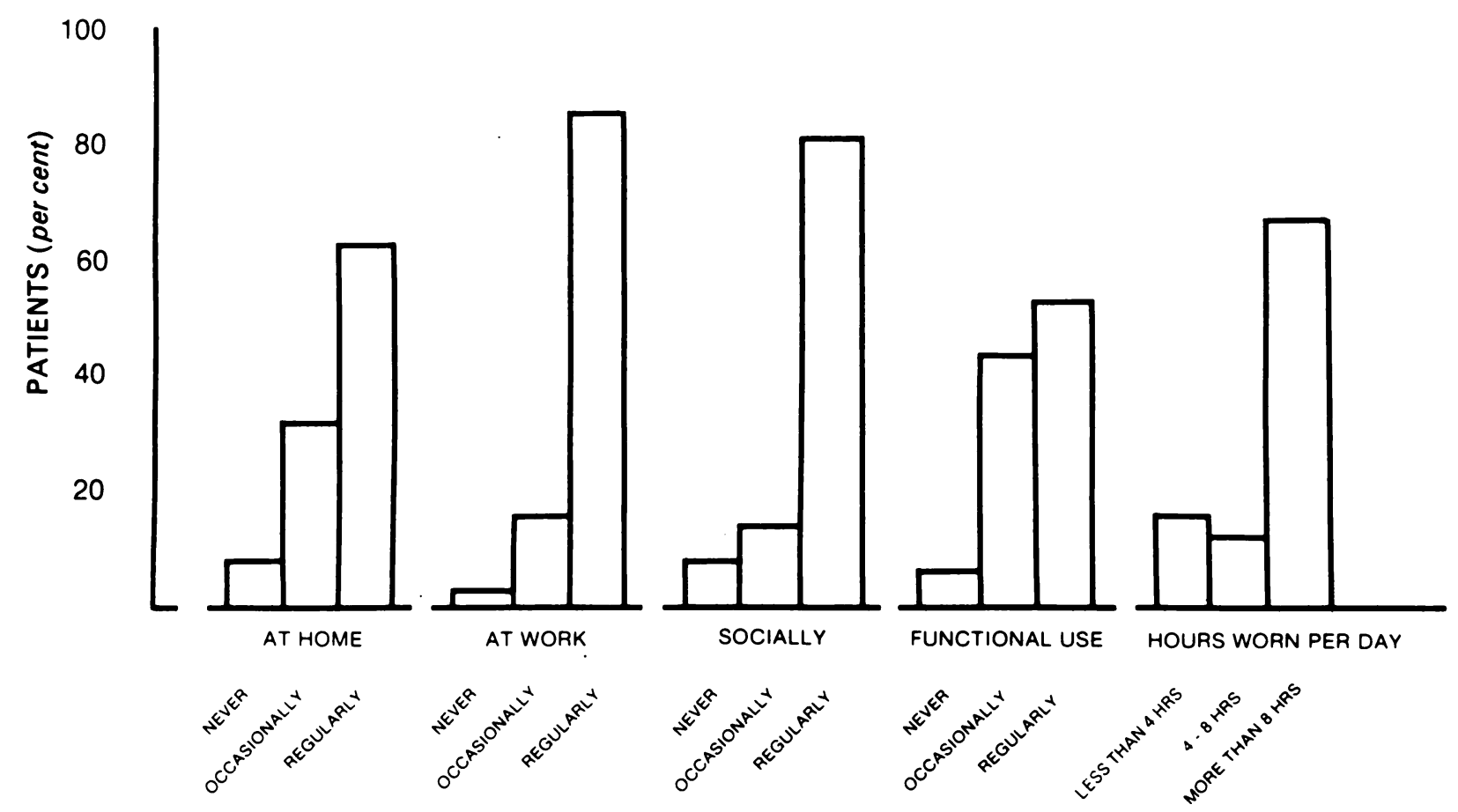

Fig. 2

Graph summarising the patterns of prosthetic use in 89 patients.

possibly representing the time when the children began to realise that a prosthesis did not satisfy their functional needs. The most common reason the children gave for abandoning their prosthesis was that they could manage just as well without it. A significant number gave up in their early teens as, understandably, embarrassment about their appearance became a more significant factor. Among the amputees, all the drop-outs had occurred during the teenage years.

Prosthetic use by those patients still wearing a device was estimated by the number of hours it was worn per day and whether it was worn at home, at work, or socially. Functional use of the prosthesis was also determined as accurately as possible (Fig. 2); it was impossible to obtain accurate data without observing patients individually over a prolonged period. Two interesting facts, however, emerged from this part of the study. First, there was no difference in patterns of prosthetic use between those children fitted over the age of two years from those fitted under two years of age. Thus, provided a patient who is fitted after two years of age manages to persist with his prosthesis, he becomes every bit as good a user as somebody fitted under two years of age. Secondly, a specific group of 14 patients was identified who only used their prosthesis for a particular function; this was usually a sporting activity or other recreational pursuits.

Twenty-eight children in the series, initially fitted with a conventional prosthesis, were subsequently fitted with a myoelectric prosthesis. Nine of these patients still found occasional uses for their conventional prosthesis, while four had reverted to their conventional prosthesis.
The perceived benefits of a myoelectric prosthesis appeared to be cosmesis, improved function and the fact that a harness was not required. The return to wearing a conventional prosthesis in four patients was due to the increased maintenance demands of the myoelectric prosthesis. This finding correlates closely with the work done in adult amputees fitted with a myoelectric prosthesis (Northmore-Ball, Heger and Hunter 1980).

\section{DISCUSSION}

Our study has clearly demonstrated the value of early prosthetic fitting in reducing the drop-out rate of prosthetic wear. The higher drop-out rate reported in this series compared with that of Brooks and Shaperman (1965) is a reflection on our longer follow-up period through childhood and adolescence.

At best, a prosthesis is a useful tool to assist the normal limb. It is unrealistic to expect that it can ever replace the function of a normal limb. At the worst, it may be an unaesthetic, heavy encumbrance.

It must be remembered that a deficient limb's most useful function is frequently as a sensory organ. When the limb becomes encased in a prosthesis this function becomes impaired. Although a prosthesis may provide some sensory feedback through the socket and harness (Rohland 1974) this is inadequate compared with that from the sensory nerve endings on the skin, and must represent a significant reason for the prosthesis being abandoned. This is confirmed by our results which showed that as the level of deficiency moves down the forearm, so the drop-out rate becomes steadily higher, 
since the longer the stump, the more useful it becomes as a sensory tool.

Our study has shown that patients may give up wearing a prosthesis many years after it was fitted, indeed, 18 of our patients gave up wearing a prosthesis after 13 years of age. Embarrassment because of the cosmetic appearance of a hook as a terminal prosthetic device was an important factor in this group. Perhaps patients give up their prosthesis at this age, when, with a little encouragement they might persist. Group therapy in teenage groups could provide one solution to this problem.

In conclusion, we have demonstrated a dramatic increased acceptance rate if the patient is fitted under two years of age, and have pointed out some reasons for prosthetic failure. Only by closer attention to failures can deficiencies in prosthetic care and rehabilitation services be highlighted, so that hopefully, in the future, a greater rate of acceptance and an improved pattern of use will be achieved.

We wish to thank Dr D. Gibson, Medical Director of the Ontario Crippled Children's Centre, for his helpful advice during the preparation of this paper. We are also indebted to Mrs M. Braithwaite who typed the manuscript, and to the Department of Medical Illustrations at St Joseph's Health Centre for providing the illustrations.

\section{REFERENCES}

Aitken GT, Frantz CH. The juvenile amputee. J Bone Joint Surg [Am] 1953;35-A :659-64.

Brooks MB, Shaperman J. Infant prosthetic fitting: a study of results. Am J Occup Ther 1965;19:329-34.

Fisher AG. Initial prosthetic fitting of the congenital below-elbow amputee: are we fitting them early enough? Inter-Clinic Information Bulletin $1976 ; X V(11-12): 7-10$.

Lund A. Observations on the very young upper extremity amputee. Am J Occup Ther 1958;12:15-22.

Northmore-Ball MD, Heger H, Hunter GA. The below-elbow myo-electric prothesis: a comparison of the Otto Bock myo-electric prosthesis with the hook and functional hand. J Bone and Joint Surg [Br] 1980;62-B:363-7.

Rohland TA. Sensory feedback in upper-limb prosthetic systems. Inter-Clinic Information Bulletin 1974;13 (9):1-4.

Sörbye R. Myoelectric prosthetic fitting in young children. Clin Orthop 1980;148:34-40. 